\title{
1 Slash 100\%: gamification of mathematics with hybrid QR-based card game
}

\author{
Ong C. Yung ${ }^{1}$, Syahrul N. Junaini ${ }^{2}$, Ahmad A. Kamal ${ }^{3}$, Laili F. Md Ibharim ${ }^{4}$ \\ ${ }^{1,2}$ Faculty of Computer Science and Information Technology, Universiti Malaysia Sarawak, Malaysia \\ ${ }^{3}$ Centre for Pre-University Studies, Universiti Malaysia Sarawak, Malaysia \\ ${ }^{4}$ Faculty of Art, Computing \& Creative Industry, Universiti Pendidikan Sultan Idris, Malaysia
}

\begin{tabular}{l} 
Article Info \\
\hline Article history: \\
Received Mar 1, 2020 \\
Revised May 17, 2020 \\
Accepted Jun 2, 2020 \\
\hline
\end{tabular}

\section{Keywords:}

Game-based learning

Interactive learning

Mathematics education

Serious game development

STEM

\begin{abstract}
Mathematics is vital in our life and society. However, gamification of mathematics is rare for topics such as fractions and decimals. This paper presents the development of an educational mathematics game called one slash one hundred percent (1 Slash 100\%). It is the hybridization of the conventional card game and quick response (QR). This research aims to study how the respondents explore the card game to master decimal, fraction and percentage. The testing was conducted among secondary school students in Kuching, Sarawak, Malaysia $(\mathrm{n}=12$; age $=14)$. The respondents were asked to answer a set of questions in pre-test and post-test question. The results are promising where the analysis showed a significant difference between pre-test $(\mathrm{M}=14.3, \mathrm{SD}=2.103)$ and post-test scores $(\mathrm{M}=17.6, \mathrm{SD}=2.234)$. Thus, gamification of mathematics using the hybrid card game increases their mastery of decimal, fraction and percentage.
\end{abstract}

\section{Corresponding Author:}

Syahrul N. Junaini,

Faculty of Computer Science and Information Technology,

Universiti Malaysia Sarawak (UNIMAS), 94300 Kota Samarahan, Sarawak, Malaysia.

Email: syahruln@unimas.my

\section{INTRODUCTION}

Mathematics is an important subject and critical skill to master for us to function in a society [1]. It involves cognitive activities such as logical and reasoning through calculation [2]. The subject of mathematics is related to quantity, numbers, measurement and other related concepts. However, gamification of the mathematics subject is still rare, especially for topics such as Linear Algebra and fractions [3]. Thus, learning institutions such as schools should tap the power of mobile-learning to fulfil the current learning needs of the new millennial learners [4]. This paper presents the development of an educational mathematics game called one slash one hundred percent (1 Slash 100\%). It combines the concepts of card games and quick response $(\mathrm{QR})$ technology. It intends to help students to master fractions and decimal, based on the curriculum and assessment standards document (DSKP) produced by the ministry of education (MOE), Malaysia.

We intend to make it easier to form 3 students to understand and master the concept within a short amount of time. As fraction is one of the toughest syllabi for students [5], our main research question is to find methods that could combine both the conventional card game and QR to improve learning further. This paper is structured as follows: Section 2 discusses a brief literature review and related works. Section 3 describes the process of designing the QR card game. Meanwhile, section 4 presents the methodology of the evaluation method. Section 5 explains the results of the game testing process. Section 6 discusses the main challenges in designing our mathematics card game. Finally, Section 7 summarizes the project and presents future research opportunities. 


\section{GAMIFICATION OF MATHEMATICS}

Card games have been around for hundreds of years. It was reported to have started in China during the Tang dynasty. Card games involve techniques, insights and discipline. The players need to develop their strategy to win. Educational card games introduce the students with the complex learning process at different levels of difficulties. Besides, card games are good to educate children about patience, sportsmanship, motor skills, listening skills and concentration. Therefore,card games may become an effective educational strategy to promote active learning. A study conducted by [6] suggested that embedding abstract mathematics strategy is an essential aspect of mathematics games. In this era, non-electronic math games still offer teachers and parents to have 'play talk' while playing as opposed to digital math games and apps [7].

Previous studies have emphasized that Game-based Learning (GBL) has positive motivational effect among students [8]. A study by [9] argued that positive mathematics experiences among students at an early stage might have a more prolonged effect on their mathematics performance. Any intervention such as GBL may provide educators with immediate diagnosis and correction tools. Researcher [10] supported this argument by suggesting that a simple, low-fidelity math card game may improve numerical skills, especially among 39 low-income children in their study. Game-based learning impacts students' enthusiasm, commitment, and enjoyment [11]. Besides, an app called 'DorDor' was developed by [12] to prove that Digital Game-Based Learning (DGBL) with Augmented Reality (AR) is useful in mathematics. An extensive qualitative study involving 3,202 participants revealed several reasons why learners enjoy learning gamification [13]: (i) it fosters enthusiasm; (ii) it provides performance feedback; (iii) it fulfils learners' needs for gratification; and (iv) it promotes goal setting.

Furthermore, it can also boost mutual relationships among the teachers and students in fun and enjoying way. A study by [14] found that 39 students in Indonesia faced difficulties in understanding mathematics problem out of fear and anxiety. Difficulty in understanding arithmetic, in general, is typical among children [15]. Thus, the mathematics card game is an alternative way to enhance the process of learning. It also motivates and helps them to understand better while enjoying the non-serious learning process as well as improve their learning performance [16].

Also, QR-based Math card games can innovate the learning process by providing a robust and competitive platform for students. Researcher [17] believed that competition and the urge to score points has the power to increase learners' engagement. Collaborative learning and social-based learning through mobile QR technology is an excellent alternative to conventional learning. Thus, more and more QR-based math game design models should be developed and validated based on established models such as the technology acceptance model (TAM) and technology readiness index (TRI) as done by [18]. The hybridization of physical and digital interactive mathematics card games could overcome the challenges related to learning performance [19]. This is because significant contributions of mobile learning technologies in recent years have successfully built the learners character, behaviour and interest [20]. Recently, reseacher [21] developed a mathematics board game called Mathboard that used Internet of Things (IoT) technology.

\section{DESIGNING 1 SLASH $100 \%$ QR-BASED GAME}

In this card game, players are required to find the answer to question cards to win the game. There are power cards added to make the card game exciting and enjoyable. The instructions to play this card game is easy to understand. The players may find the hint for the question card provided at the bottom of the card. This card game covers three chapters starting from Form 1 to Form 3, which are decimal, fraction and percentage. In the deck, there are 56 cards, with 36 number cards and 20 power cards. Example of question cards is shown in Figure 1.
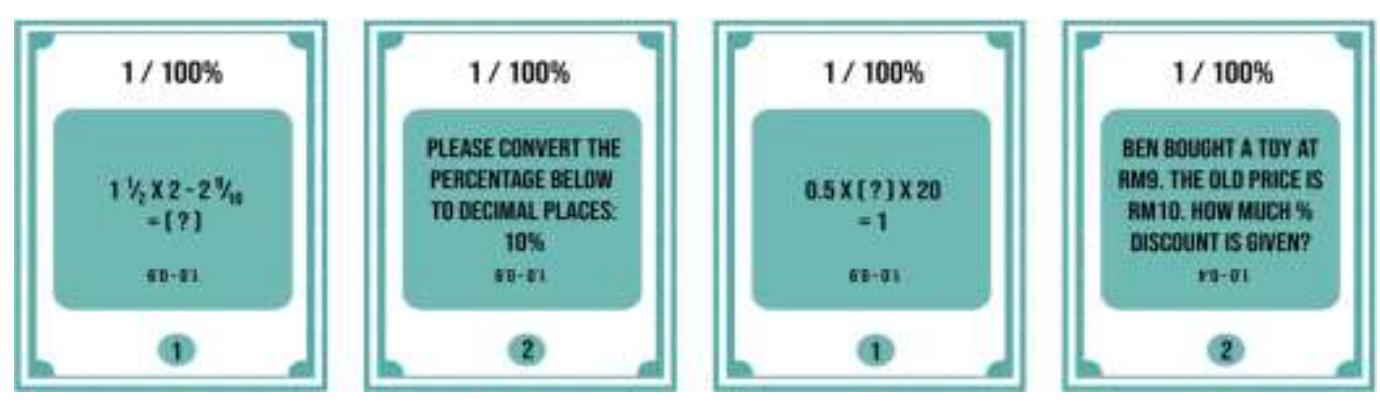

Figure 1. Question cards 
Figure 2 shows the card game box design. The design is simple to attract students to focus on the educational content of the game. Figure 3 shows the QR codes embedded on the game package that links to the YouTube videos or channel. Figure 4 shows the QR codes that are linked to a YouTube channel. Short videos were created to explain various subtopics.
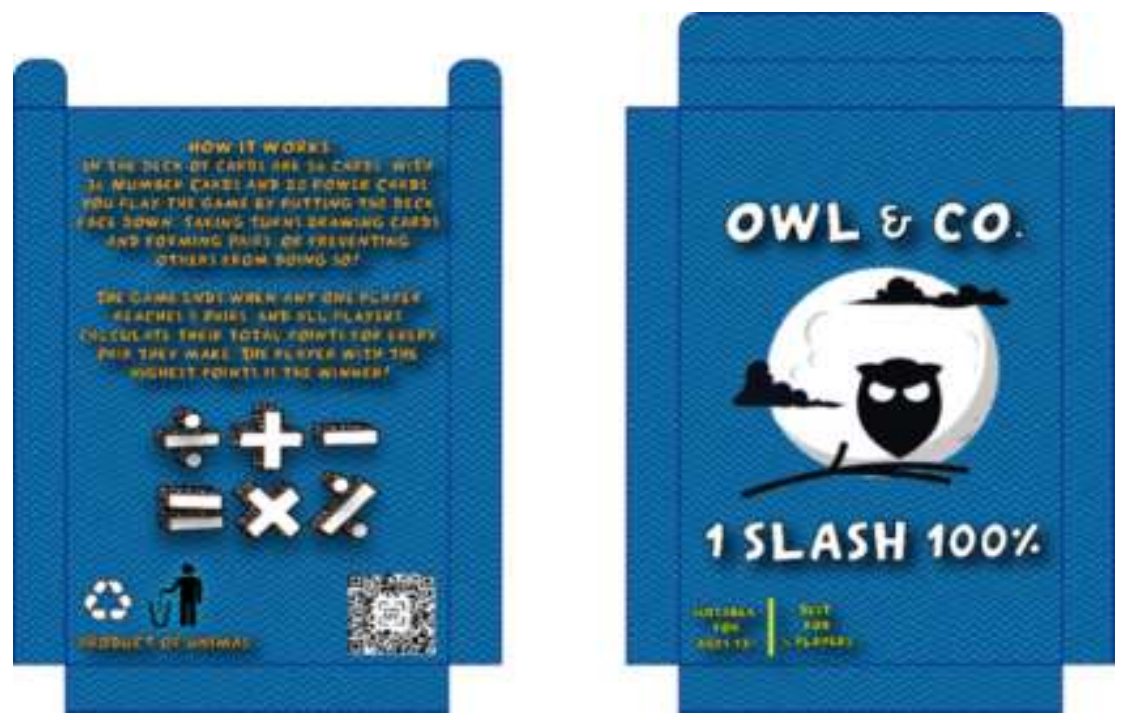

Figure 2. Game box design (back and front)

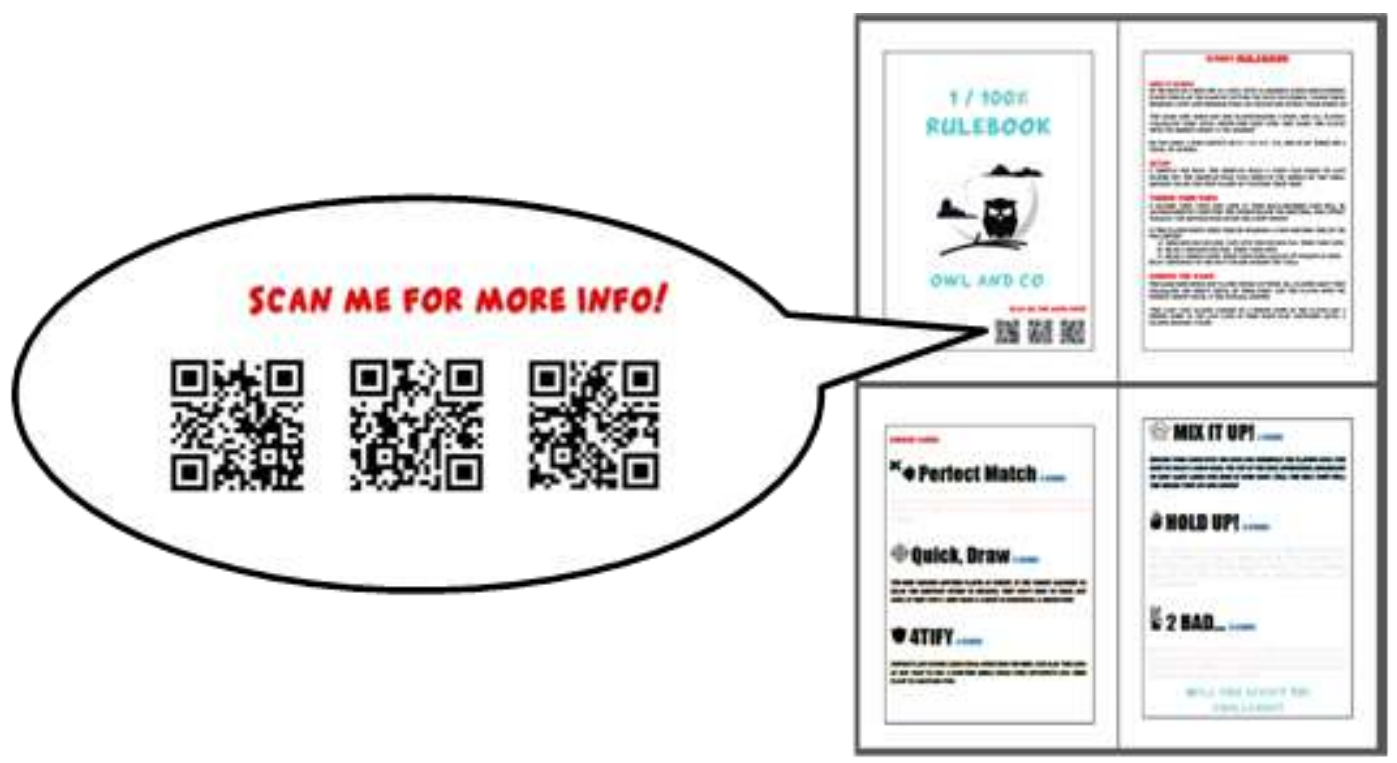

Figure 3. QR access code printed on the rule book, linked to the instructional videos and fun:

There are Power cards that can be seen in Figure 5 designed to make this game more challenging

- Perfect Match cards will enable the players to form a Pair with any Number card, but only points from the Question card will be calculated.

- 2 Bad! cards will enable the players to force any other opponents to draw two cards.

- 4tify cards will enable the players to prevent Power cards from affecting them, and it gives the players a shield from the opponents at any time.

- Mix It Up! cards will enable the players to reshuffle his or her cards and place it into the deck and draw three cards, regardless of how many cards he or she currently holds. 
- Hold Up! cards will eliminate a target's Pair and forces them to discard that Pair, drawing one card from the deck and is playable at any time.

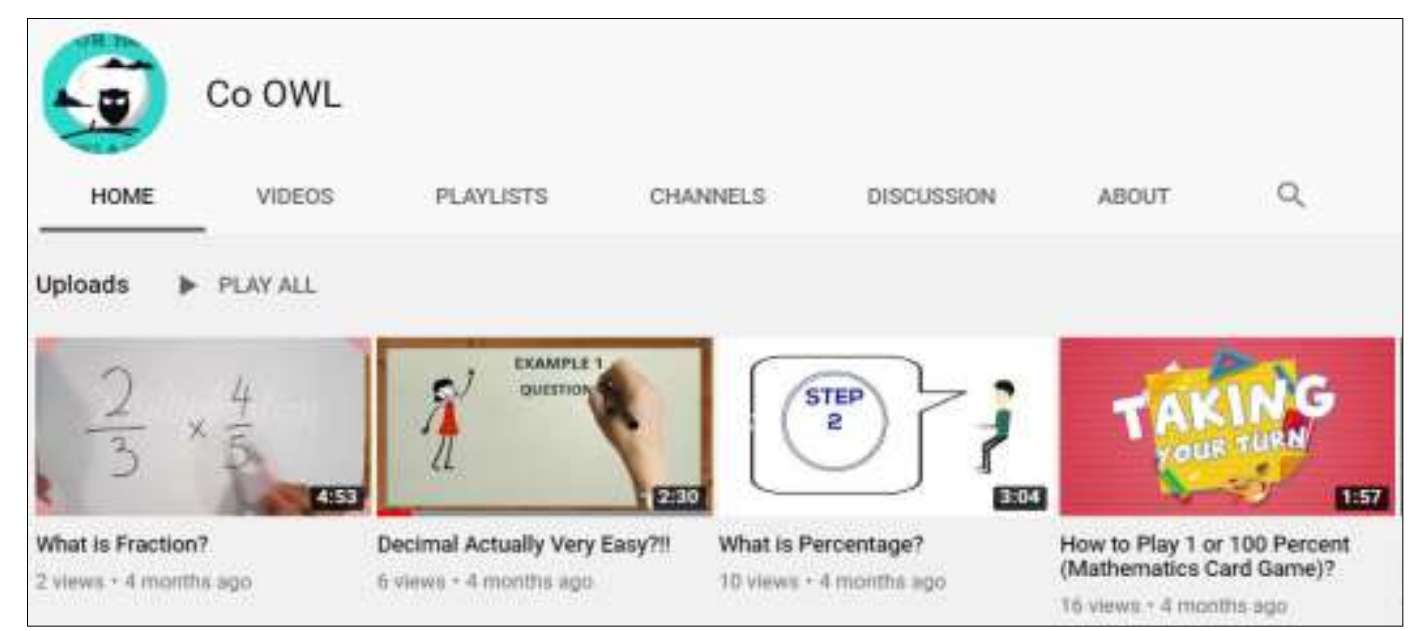

Figure 4. The QR codes are linked to a YouTube channel
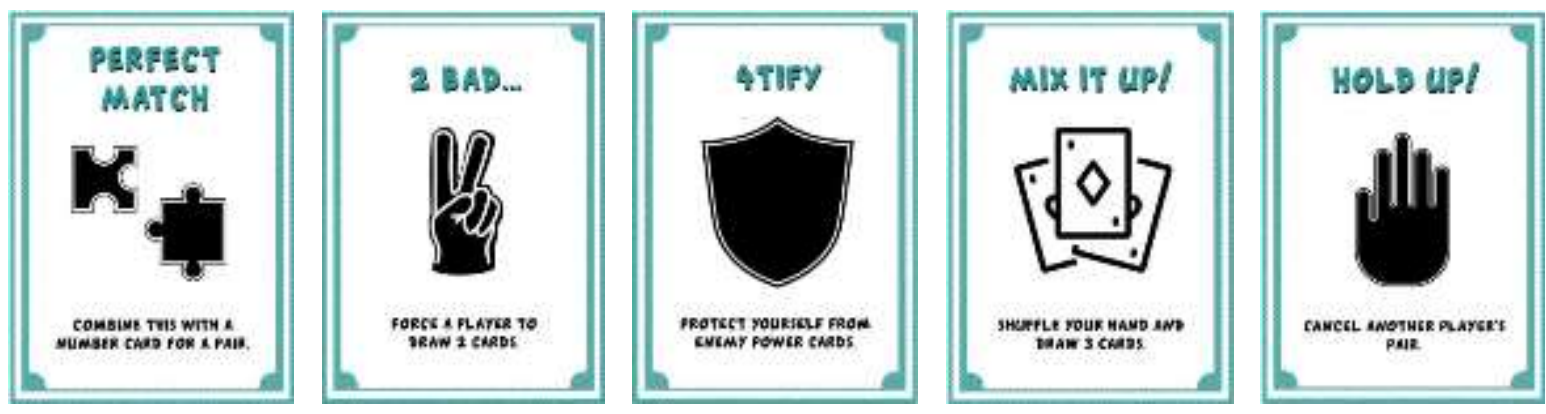

Figure 5. Power cards

To start, a player must shuffle and distribute the cards. The shuffler will give five cards to each player (face-down) and put the shuffled deck in the middle of the table. The oldest player by default becomes the first player. Play turn by turn clockwise. All players must put the deck facing down, taking turns drawing cards and forming pairs, or preventing others from doing so. The game will end when any player has collected five pairs of cards. All players must calculate their total points for every pair they made. The player with the highest total point is the winner. Each Question card will be accompanied by a hint of the answer below the question, and a point value displays the Question card's point value. Next, the player will start their turn by drawing a card and does one of the following:

- Play and discard one card into the discard pile, and their turn ends.

- Play a designated pair, and their turn ends.

- Play a power card, and their turn ends unless the second chance card is used.

Then, the game will continue with the next person around the table. The game will end when any player forms a fifth designated pair. All players must then calculate the point total of their pairs, and the player with the highest point total is the overall winner. The last card played cannot use a power card. If the player has a power card as the last card in their hand, they must draw a new card.

\section{GAME EVALUATION METHOD}

Pre-test and post-test were the instruments used in the study. A user testing was carried out among 12 students $(\mathrm{Age}=14)$ at a school in Kuching, Sarawak, Malaysia $(\mathrm{m}=6, \mathrm{f}=6)$. The objective of the testing session is to obtain feedbacks, comments and suggestions for improvements to our card game. 
Before the testing started, we explained the objectives of the game and the function of the power cards that will be used to play the game. The students were divided into three groups. Firstly, the pre-test was conducted among the students. The test consists of of 20 questions. Each group took approximately 30 minutes to complete the game. After playing the card game, the students were given a post-test. The tests were conducted to evaluate their understanding. While playing the game, the students were able to learn about the topics indirectly. We also observed the players' behaviour that can be seen in Figure 6 .

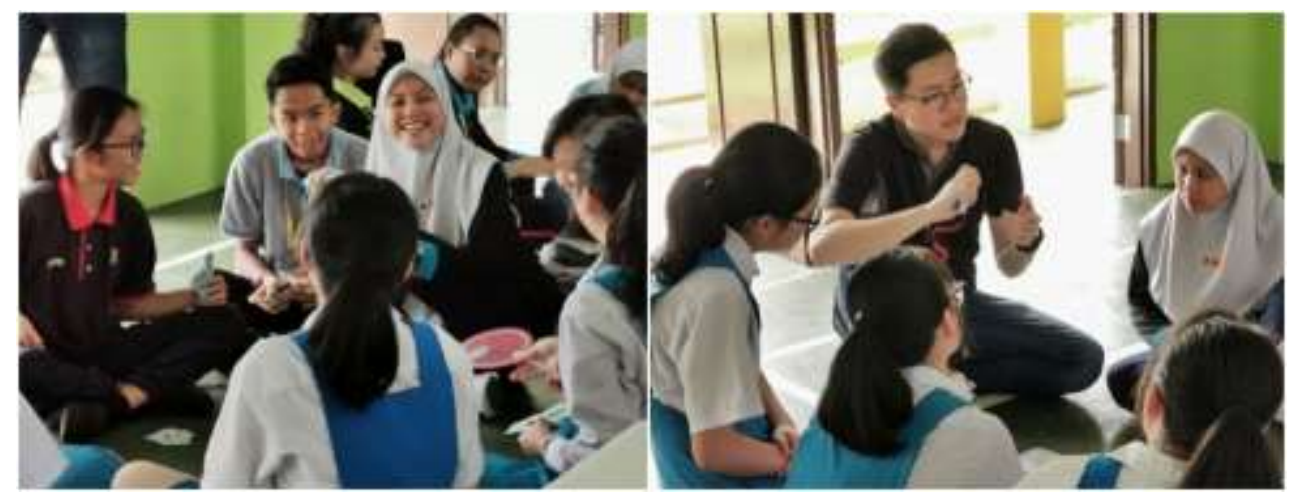

Figure 6. Instructing the students on how to play the game

\section{RESULTS AND ANALYSIS}

This section explains our findings based on our experience during the playtest session. After analyzing the results of both tests, it is concluded that the results of post-test were better than the pre-test. The results obtained are displayed in Figure 7. The analysis showed a significant difference between the pre-test $(M=14.3, S D=2.103)$ and post-test scores $(M=17.6, S D=2.234)$. The results suggest that the students' performance in the post-test was significantly higher than that in the pre-test. This proves that most of the respondents have improved after playing our QR card game by correctly solving more questions. Based on our observation, we noticed that the students enjoyed the game.

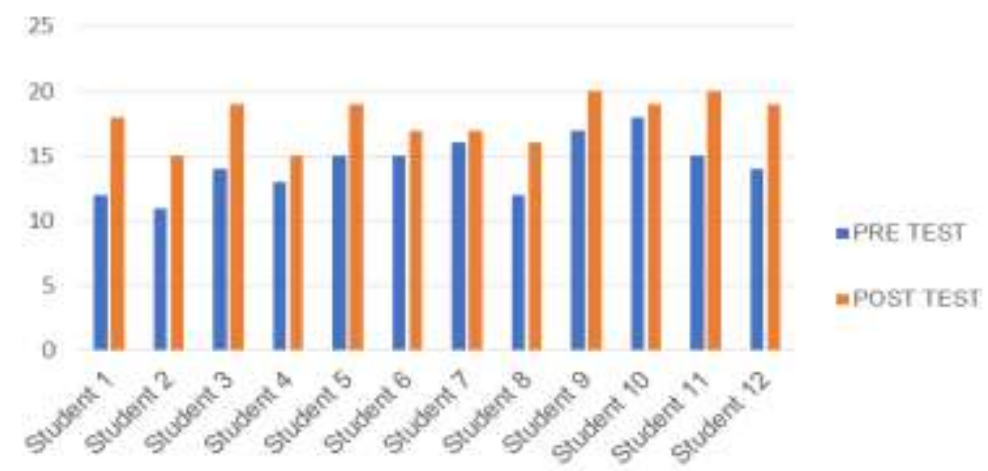

Figure 7. Pre-test and post-test results

For the discussion purpose, generally, we know that mathematics is quite a boring subject for students. This may be due to the conventional method of teaching math, which is somehow uninteresting. There is either no or little fun factor. Moreover, there is less or no interaction and competition among students, and there are only few or no exciting parts. The conventional way of chalk and talk makes the students to easily feel bored. Eventually, they would lose their interest. This traditional way of teaching mathematics using passive textbooks is seen as obsolete. Students cannot easily link the basic and advanced math concepts just by reading textbooks. They have been taught with the rote-learning approach for many years. They feel that it is hard to memorize abstract math concepts. Moreover, some students may have limited ability to understand abstract math concepts. 
Therefore, to fix this problem, the hybrid (analogue+digital) math card game is a new and innovative solution. The math concept is presented in a fun card-game style. This innovation may attract the students to learn the subject in an exciting method. The learning process is more effective than the conventional way. With card games, the interaction and competition factor are fundamental and essential. Hence, students would be able to learn better and faster. It provides them with a new learning experience. Most importantly, while competing for high scores, students are actually learning the educational mathematics content. The learning outcomes are achieved. Mathematics card games would help the students to remember math formula better. Besides, this way of learning is more interesting, more fun and more unique.

Besides, our maths card game has an attractive design despite having challenging questions. Our design was supported by [22] who stated that game design should offer excellent and convenient control, as well as adequate information to the players. As a result, the students would develop more reliable memory on math topics. The gamification approach involves rewards and punishments. The gamified math card game would make the students fall in love with mathematics. They may improve their confidence in content mastery. Besides, math card game ensures the students apply the math concepts in solving the game questions. Our unique QR-based card game has successfully introduced fraction mastery to the students as competency in decimal and fraction is a basic for more complex calculations [5].

For the implication of this paper, teachers and educators are encouraged to deploy the QR-based math card game in their classroom. QR-based video embedded in our card game supports the statement by [23]. They mentioned that short duration videos with suitable music are favoured by students. This is because it will allow the students to memorize the learning content. Beyond QR-linked videos, educators may embed QR-based mathematics games using virtual reality videos [24]. However, we understand that more rigorous studies are needed to look into the usability of the proposed intervention and should cater to their cognitive loads $[13,25]$.

\section{CONCLUSION}

In conclusion, the gamification approach we used in designing has made 1 Slash 100\% an interesting and fun hybrid mathematics card. We believe that this card game would greatly benefit students and can be used as an effective learning material besides formal learning. Our card game managed to make learning mathematics more fun. In the future, we will extend our work to also include VR and AR technology. We also plan to explore other recent technologies such as IoT to relate to our hybrid card game.

\section{ACKNOWLEDGEMENTS}

We would like to express our appreciation to Universiti Malaysia Sarawak for providing us with a grant to fund this research (F08/SpMYRA/1661/2018). Thanks to Loke Ming Kang, Azmi Su'aidi Arifin, Nurayin Bahrin, Amirul Azridin Saaiddin, Nursyafiqa Mohd Jelani, Wong Xin Zi, Wilson Teng Wei Sung, Kevin Tiong Kung Zhao, Leong Kok Yieng, Wong Xin Zi and Syahirawati Pasin for their invaluable support in the development and testing phase.

\section{REFERENCES}

[1] R. O. Kellems, G. Cacciatore, and K. Osborne, "Using an Augmented Reality-Based Teaching Strategy to Teach Mathematics to Secondary Students With Disabilities," Career Dev. Transit. Except. Individ., vol. 42, no. 4, pp. 253-258, 2019.

[2] W. Chao, C. Yang and R. Chang, "A Study of the Interactive Mathematics Mobile Application Development," 2018 1st IEEE International Conference on Knowledge Innovation and Invention (ICKII), 2018, pp. 248-249. doi: 10.1109/IC KII.2018.8569126.

[3] R. H. A. Rahim, A. Baharum, and H. Hijazi, "Evaluation on effectiveness of learning linear algebra using gamification,” Indones. J. Electr. Eng. Comput. Sci., vol. 17, no. 2, pp. 997-1004, 2019.

[4] A. Baharum et al., "Mobile learning application: Flipped classroom," Indones. J. Electr. Eng. Comput. Sci., vol. 17, no. 2, pp. 1084-1090, 2020.

[5] J. M. Namkung, L. S. Fuchs, and N. Koziol, "Does initial learning about the meaning of fractions present similar challenges for students with and without adequate whole-number skill?," Learn. Individ. Differ., vol. 61, pp. 151-157, 2018.

[6] P. J. McFeetors and K. Palfy, "Educative experiences in a games context: Supporting emerging reasoning in elementary school mathematics," J. Math. Behav., vol. 50, pp. 103-125, 2018.

[7] E. L. Zippert, E. N. Daubert, N. R. Scalise, G. D. Noreen, and G. B. Ramani, "Tap space number three': Promoting math talk during parent-child tablet play,” Dev. Psychol., vol. 55, no. 8, pp. 1605-1614, 2019.

[8] B. Taspinar, W. Schmidt, and H. Schuhbauer, "Gamification in education: A board game approach to knowledge 
acquisition," Procedia Comput. Sci., vol. 99, pp. 101-116, 2016.

[9] P. S. Moyer-Packenham et al., "How design features in digital math games support learning and mathematics connections," Comput. Human Behav., vol. 91, pp. 316-332, 2019.

[10] G. B. Ramani and N. R. Scalise, "It's more than just fun and games: Play-based mathematics activities for Head Start families," Early Child. Res. Q., vol. 50, pp. 78-89, 2020.

[11] D. Vlachopoulos and A. Makri, "The effect of games and simulations on higher education: a systematic literature review," Int. J. Educ. Technol. High. Educ., vol. 14, pp. 1-23, 2017.

[12] F. A. Pritami and I. Muhimmah, "Digital game based learning using augmented reality for mathematics learning," ACM Int. Conf. Proceeding Ser., pp. 254-258, 2018.

[13] S. M. M. de Mooij, et al., "Should online math learning environments be tailored to individuals' cognitive profiles?," J. Exp. Child Psychol., vol. 191, p. 1-15, 2020.

[14] M. R. Novriani and E. Surya, "Analysis of student difficulties in mathematics problem solving ability at MTs SWASTA IRA Medan,” Int. J. Sci. Basic Appl. Res., vol. 33, no. 3, pp. 63-75, 2017.

[15] Ann Dowker, "Chapter Seven-Interventions for Primary School Children With Difficulties in Mathematics," in Advances in Child Development and Behavior, vol. 53, pp. 255-287, 2017.

[16] K. Awang, et al., "The usability analysis of using augmented reality for linus students," Indones. J. Electr. Eng. Comput. Sci., vol. 13, no. 1, pp. 58-64, 2019.

[17] F. Fisher, J. Warner, and N. Mickelson, "Cardboard Cities, Real Mathematics: Employing Quantitative Literacy to Study Gentrification in NYC," Primus, vol. 29, no. 9, pp. 908-927, 2019.

[18] R. A. Majid and J. C. Hasim, "The effectiveness of frog VLE implementation: Students' perspective," Indones. J. Electr. Eng. Comput. Sci., vol. 14, no. 1, pp. 381-387, 2019.

[19] K. Tabassum, "Using wireless and mobile technologies to enhance teaching and learning strategies," Indones. J. Electr. Eng. Comput. Sci., vol. 17, no. 3, pp. 1555-1561, 2020.

[20] M. Gasah, A. Baharum, and N. H. M. Zain, "Measure learning effectiveness among children using EEG device and mobile application,” Indones. J. Electr. Eng. Comput. Sci., vol. 17, no. 1, pp. 191-196, 2019.

[21] L. P. Madrid and F. Lorenzi, "Mathboard: An intelligent object for use in educational activities," Acta Sci., vol. 21, no. 3, pp. 59-74, 2019.

[22] S. H. Lee and D. H. Song, "Functional usability analysis of top korean mobile role playing games based on user interface design," Indones. J. Electr. Eng. Comput. Sci., vol. 13, no. 1, pp. 123-128, 2019.

[23] M. R. Bin Husin, H. Bin Ahmad, and M. Bin Hamzah, "Video application to accommodate students' learning style for moral education in teacher education institutes," Indones. J. Electr. Eng. Comput. Sci., vol. 16, no. 1, pp. 349-354, 2019.

[24] D. Połap, K. Kęsik, A. Winnicka, and M. Woźniak, "Strengthening the perception of the virtual worlds in a virtual reality environment," ISA Trans., vol. 102, pp. 397-406, 2020.

[25] K. Schenke, et al., "Does 'Measure Up!' measure up? Evaluation of an iPad app to teach preschoolers measurement concepts," Comput. Educ., vol. 146, 2020. 